\title{
Urgences
}

\section{Lettre ouverte à nous-mêmes à propos de l'espoir et de la poésie}

\section{Gilbert Dupuis}

Numéro 1, 2e trimestre 1981

URI : https://id.erudit.org/iderudit/025001ar

DOI : https://doi.org/10.7202/025001ar

Aller au sommaire du numéro

Éditeur(s)

Urgences

ISSN

0226-9554 (imprimé)

1927-3924 (numérique)

Découvrir la revue

Citer ce document

Dupuis, G. (1981). Lettre ouverte à nous-mêmes à propos de l'espoir et de la poésie. Urgences, (1), 5-9. https://doi.org/10.7202/025001ar d'utilisation que vous pouvez consulter en ligne.

https://apropos.erudit.org/fr/usagers/politique-dutilisation/ 


\section{GILBERT DUPUIS}

\section{Lettre ouverte à nous-mêmes à propos de l'espoir et de la poésie}


Que le dernier désespéré rentre dans les gencives des sirènes ou des poulamons, sous le pont du choix final, n'empêche pas le sablier du monde de garder et de parfaire sa job à plein temps! L'hiver définitif des uns ne fait guère frissonner la surface du Temporel qui n'a pas une seconde à perdre avec tout un chacun qui suit sa tête partout...

A nous donc tous les frémissements par goût, par habitude ou par désespoir. A nous le couraillage après son souffle malgré le travail des grains de sable sur la chair. A nous la vie pendant la vie. A nous le labeur sur soi, les défis du désir, à nous tous les états de coeur. Tous les univers du monde ont la bougeotte et nous avons bien peu d'appareils dans notre orbite. La boîte à outils du commun est un coffre sans sésame. Nous avons bien peu de renard dans notre livre et de prince n'en voulons pas, même petit. Et le brouillard ne manque pas et tous nos yeux ne sont pas de trop pour inventer des horizons tolérables.

Nous avons besoin de chercheurs au long cours, de nommeurs conjoncturaux et d'expérimentateurs bavards, nous avons besoin de vigies généreuses et de rapporteurs de mondes. Autant le dire tant qu'à le songer, nous avons plus à faire que des autopsies satisfaites et plus à prendre que des pauses avant la sueur. Nous avons pêle-mêle besoin de perroquets du coeur, d'allumeurs de torches, de gigotteurs de pommiers, de trafiquant d'oxygène en gros, nous avons besoin de paniers percés dans nos propres mots... Et qui tirent des paroles de tout ce qui parle et qui les mettent en musique pour chanter les femmes et les hommes en toute subjectivité informative, en toute objectivité personnelle! 
La poésie doit à la fois nous précéder et nous attendre. Elle se doit à nous, la poésie. Même si parfois la part des dieux en elle échappe à l'inventaire de nos clefs. Même si le verbe et le geste déraillent de voies familières à nos gares. La poésie est le sixième sens et tous les autres. Elle passe dans la façon de concerner le dedans qui contient l'alentour. Le plaisir de flirter les contours du mélodrame cocasse de vivre la connaît. Comme la reconnaît, l'homme attentif à la tension des choses entre elles et qu'il regarde en face (les choses). Ce fluide des révélations coule par-devers l'assoiffé de naissance, ce deuxième sang donne des yeux au premier, cette huile sans nom a plusieurs synonymes. La poésie, le transport intime, la conscience de la conscience, l'apprivoisement des abîmes, le goût des allumettes, le suspense de la prescience, sa re-création au propre, la poésie.

Ce qu'on imagine réalité et ce qu'on réalise imaginaire attendent un liquide décapant pour se faire voir et pour se faire à notre histoire. La nuit est-elle l'absence de jour ou sa présence imparfaite? Un cigare est aussi un cigare (Freud). Tout est dans tout et vice-versa. Les mystères de la rue et du journal froissent un peu l'agenda au-dessus de la montre. Nous sommes des crânes magnétiques cherchant le nord des planètes habitables. La ligne du risque, les aléas de l'appétit, l'anxiété des mutilations, l'euphorie des baptêmes, l'échéance de l'épitaphe et le goût encore de posséder sa vie. Tel est notre moyen de ne pas reculer, en connaissance de causes et d'effets et de soi. La poésie, la matière et la manière, l'outil et le meuble, la vie et le vivant. Je ne dis rien d'une façon verbale ou picturale d'exister qui s'approcherait d'une négation de l'existence. Je veux parler du désir, du moteur, je veux parler de la poésie, de l'essence. Et je nous les rends mutuellement inclusifs, l'espoir et la vie. Et c'est aux femmes et aux hommes qu'elle se doit la poésie avec toujours des arrière-pensées d'espérance dans le dessein malgré les arrière-goûts de désespoir dans son destin... 
Il faut se défier dans ce pays-ci des attendrissements passéistes et des nostalgies de coureurs des bois. A moins que ces regards par-dessus l'épaule éclairent davantage la piste des projets et qu'ils trempolinent mieux l'artiste des ascensions exploratoires. Bon. A moins que tous ces moutons antérieurs pissent de l'huile dans l'engrenage actuel des contradictions et qu'ils défrisent l'écheveau des réconciliations à faire. Il faut garder la vigilance de son bord pour jauger les présents et l'immédiat, pour fonder son ciel dans l'une des nuances du bleu.

J'appelle des énergies pour faire vivre l'utopie de la liberté joyeuse, pour allumer le rêve d'une amoureuse qui dirait oui tous les matins, j'appelle la fiction de l'éternité dans le corps et dans la ville que j'aime. Car les espaces de vivre nous parlent des vivants qui les bûchent et les façonnent. Et nos places de vie prennent l'allure des intrants. La ville se bâtit de sueurs d'hommes et de femmes, de joies, de peines et de misères à ne pas dénigrer la ville sans risquer le reniement du précieux temps des charpentiers, sans désennoblir l'ouvrage et l'application; la ville est pleine du même monde qui aime les enfants à la folie et qui est lâche aussi et qui fait l'idiot du village certaines nuits. Je tenais à dire "à chacun son bruit, à chacun sa promenade" et que tout le monde fait partie du monde.

Qu'est-ce que c'est que ces poètes qui regardent le monde sans avoir l'air d'y toucher, sans avoir l'air d'en être de l'organisation, de la ville, de la consommation et de la statistique. Qu'est-ce que c'est que ces mal pris du souffle court au texte. Le mangeur de balustres littéraires et le drapé dans les voiles de l'innocence ponce pilate ont-ils les pieds dans le friche quotidien et l'épaule à la roue du 9 à 5 ? Manières de dire. Le poète doit brancher ses antennes sur des haut-parleurs sans filtre et des haut-faiseurs sans interlude. C'est un chasseur le poète qui lève l'espoir pour le voisinage et pour lui-même dans tous les abattis ravagés par les températures et les conjonctures. Car nous perdons notre temps si l'espoir ne nait pas des amours de la poésie et de la vie, nous perdrions notre temps je dis. 
Dire que notre imperfection nourrit une espérance: elle oblige de fait le recommencement de la connaissance et de l'apprentissage à chaque destin, je veux dire que le savoir voyage très mal dans les gènes... Nous ne superposons pas nos têtes, nous les montons une à une et je ne dis pas bibliothèques quand je dis têtes. D'où cette espérance. Car ce qui nous sauve voyez-vous c'est que nous retardons les machines, NOUS RETARDONS LES MACHINES, elles doivent nous attendre, ne pas s'emballer et n'être rien entre deux mouvements de clefs. Le siècle a beau faire scintiller ses bijoux électroniques et ses joujoux nucléaires, l'homme a des espions dans toutes les places pour forcer l'humilité dans le métal. Nous sommes les maîtres des machines, il faut qu'elles gardent leur place au sous-sol et qu'elles ne parlent pas pour nous dans les salons. Il le faudra parce qu'il le faut...

Par ailleurs, le travail de la parole devrait bien produire quelqu'espoir dans nos jours sinon la terre ne serait plus ronde et nous risquerions de tomber en bas... parce que sans lui, le respir est insolite, l'énergie tourne à vide et l'avenir reste au pied du mur. Oui à la force en soi brâlée sur l'autel de la recherche et du faire, oui aux sondages des voies impénétrées pour le moindre filon d'espérance.

Aujourd'hui. En ville ou ailleurs. Existent-ils d'autres Rimbaud Arthur, d'autres Vian Boris, d'autres da Vinci Léonardo qui tourneraient en rond dans des appartements semi-meublés et qui sauraient des sérénités de source et des lucidités démocratisables à force de gratter les plafonds bas? Mettez l'Hymne à la joie sur l'électrophone, regardez un enfant dormir et dites-moi non sans pincement. Mais est-il soluble dans la lucidité l'espoir? Qui dit limites dit-il frontières? Garderons-nous l'aval sur les machins? Le défi des impuissances stimule le magasinage de baumes au jour le jour (peut-être) et la fréquentation de certaines lumières réclame un qui-vive à prétendre entre ses tempes (sûrement). J'estime.

Et je vous affirme fraternel que pour un, je continuerai la pêche de toute la force de mes désirs patenteux tant que l'espoir ventera dans mon h... de coeur à voiles! 